appliances are made to the best of specifications, but that they should be sold at these ridiculous prices when they are of the distinctly dangerous tin-can type, liable to burst easily, is very near fraud.

It is to be hoped that the British Fire Prevention Committee will persevere in its propaganda and obtain legislation after the war is over, making it a penal offence to construct an extinguisher unless there are certain constructional safeguards to be settled from time to time by the Secretary of State as mechanical science advances. Good progress has already been made in this direction, and but for the war, the protection of the public against fraudulent fire appliances might have already been achieved.

To our readers, however, this article should serve as one of warning to insist on a written warranty before payment for any extinguishers purchased, that it complies either with the British Fire Prevention Committee's specification, or with those of the Board of Trade, H.M. Office of Works, or the Metropolitan Police. Further, for the best finished article they should not pay more than $25^{s}$. to $30 s$. when constructed to either of these specifications, but if in doubt as to the machine offered or the possibility of regularly testing and re-charging it, let them keep to the old bucket of water and hand-pump. They at least are trustworthy, and the most suitable for ordinary conditions.

\section{RESEARCH IN AERODYNAMICS. 1}

THE work of the Aerodynamical Laboratory at 1 Koutchino is less affected by the necessity for technical work than any other of the European laboratories. It is for this reason, in all probability, that the latest bulletin makes a refreshing change from the publications of Eiffel and the Advisory Committee for Aeronautics.

The production of miniature whirlwinds forms the subject of one series of experiments, and the results are illustrated by some very interesting photographs. Rotations, as apart from eddies, are of frequent occurrence in nature; they may be seen in the autumn by the movement of leaves, due to a wind over open ground. Similar movements of air are found on the floor of the room below the intake of a wind channel, and the phenomenon indicates how little we really know of the motion of real fluids.

Perhaps the most interesting papers in the bulletin are two relating to the principle of dynamical similarity as applied to viscous fluids. Experiments with the same object were made by Osborne Reynolds, and recently Messrs. Stanton and Pannell have established the practical utility of the theory in the case of air, water, and oil flowing through pipes.

One of the two papers above mentioned deals

1 Bulletin de l'Institut Aérodynamique de Koutchino. Pp. 296. Fascicule v. (Moscow: I. N. Kouchnéreff and Co., I914.)

No. 2379, VOL. 95] with experiments on the surface friction of discs in air and water, the motion being one of rotation in their own plane. The agreement between theory and practice is complete. The second paper relates to the whole of the published information on the resistance of spheres in air and water, the results being very discordant amongst themselves. The conclusion is drawn that the conditions of the theory of dynamical similarity cannot in this case be satisfied experimentally with the necessary degree of exactitude. The results of the two papers are illustrated by Figs. $I$ and 2 . The first relates to the friction of discs, and in carrying out these experiments variations were made in three quantities of primary importance, the diameter and speed of rotation of the disc and the

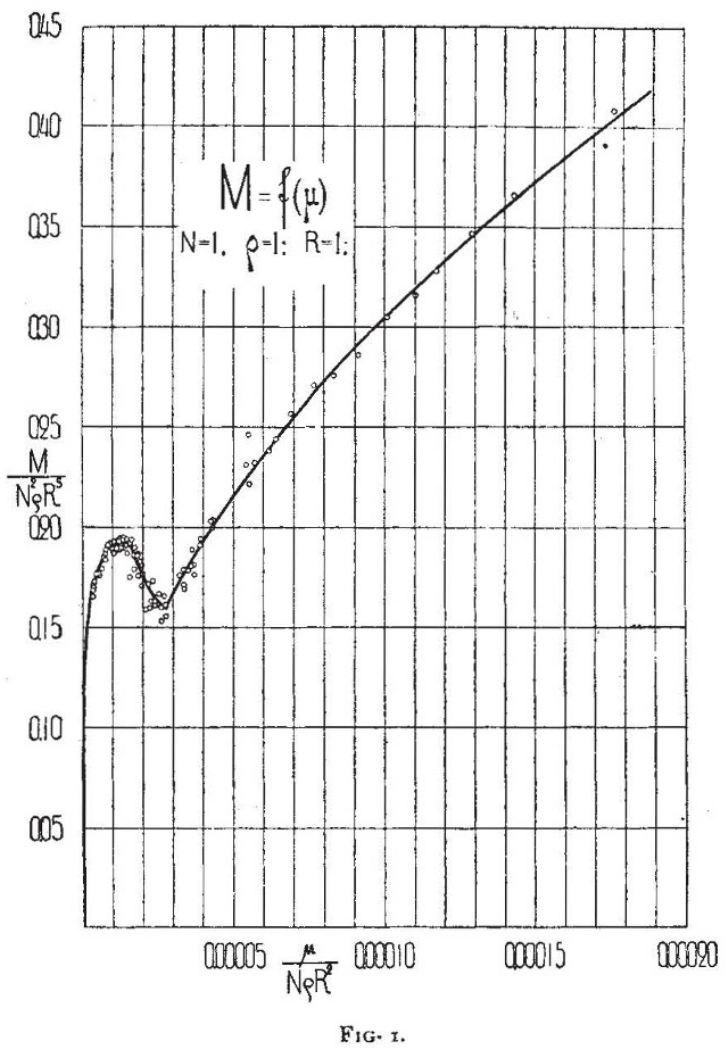

viscosity of the fluid. The ratio of the greatest diameter to the least was $10: I$, the ratio of the extreme speeds $2: \mathrm{I}$, and the ratio of the kinematic viscosities $x_{3}: x_{\text {. The theory of dynamical }}$ similarity indicates that any one of these changes can be predicted from the effect of changes in either of the others, and the practical proof of this is the fact that the whole of the experimental results can be collected on a single curve as in Fig. I. As the range of variation included a region of critical flow, as indicated by the dip in the curve, the practical agreement is a delicate test of the exactness with which the experimental conditions complied with the conditions of geo. metrical similarity. 
The reverse picture is shown in Fig. 2. The principle of dynamical similarity applies as rigidly to the resistance of spheres as to the surface friction of discs, but the experimental results vary very widely over almost the whole of the experimental range. An interesting contribution on the reasons for such large experimental discrepancies is made by Prof. Prandtl, who showed that a wire of small diameter put round a sphere in an appropriate place had the somewhat surprising effect of reducing the resistance to about one-third of that of the smooth sphere. It was further showr. that a gauze screen introduced into the air current immediately in front of the sphere had a similar effect. The conclusion appears to be justified that the flow of air round a sphere is so very sensitive that small departures from strict geometrical similarity and from the condition of uniform

\section{DR. HUGO MÜLLER, F.R.S.}

THE death of Hugo Müller will be greatly deplored by all who knew him-he was one of those few men who only make friends and at once inspire regard in all who are brought into contact with them. He died suddenly, at his country home, at Camberley, Surrey, in the early hours of Sunday, May 23, in his eighty-second year. Though very deeply distressed by the war, he enjoyed his usual good health to the last; in fact, he was in his garden until late in the evening on the previous Saturday and had worked in the Davy-Faraday laboratory up till Friday afternoon. He was buried at Brookwood Cemetery on Thursday last alongside nis old friend Dr. Atkinson.

$\mathrm{He}$ was born at Tirschenreuth in the Ober-

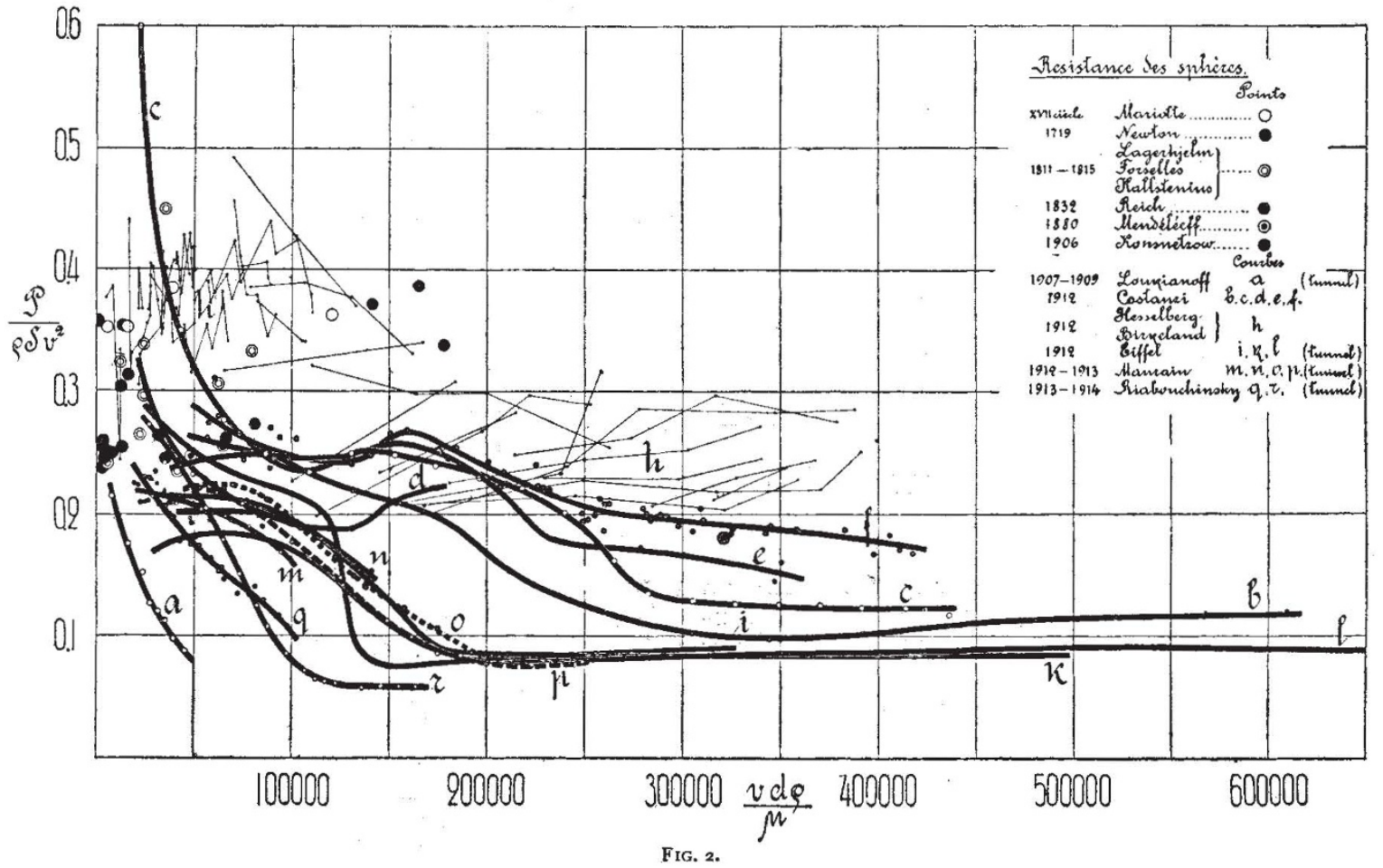

relative motion are sufficient to account for the large experimental variations.

Further experiments are needed to clear up the position, but, obviously, no investigation can alter the fact that the resistance of a sphere must always be difficult to predict, except in very favourable circumstances. The possibility at least exists that the rough surface of a golf-ball has a very close relation to the instability of flow referred to, the advantage of the roughened surface being so great as to render it obvious in the direct test on the golf links.

It is fortunate for the future of aeronautics that similar troubles do not occur in connection with the important parts of an aeroplane, though an approach to such sensitivity has been found in the case of the fluid motion round certain struts. pfalz. He was educated as a chemist at Leıpzig, at Göttingen under Wöhler and at Munich under Liebig; but he also took special interest in mineralogy and was an ardent collector of minerals in his early days. It is clear that he was a precocious worker; as he described the geognostic-mineralogical features of his home district in $185^{2}$ in the Regensburg Corresp. Blatt.

He came to this country sixty years ago, on the recommendation of Liebig, as assistant to Dr. Warren de la Rue. Their first joint work involved the examination of Burmese naphtha at a time when very little was known of the petroleums. But they took up a variety of subjects and one of their most valuable contributions was the wellknown chloride-of-silver-zinc constant battery which they devised. Dr. Müller also worked with

NO. 2379, VOL. 95] 